\title{
Valores de Motoristas de Caminhão: o que lhes causa Admiração e Indignação?
}

Truck Drivers' Values: what causes his Admiration and Indignation?

Valores de Conductores de Camión: Qué les causa Admiración e Indignación?

Luzia Teixeira Martins

Centro Universitário das Faculdades

Associadas de Ensino

Betânia Alves Veiga Dell' Agli

Universidade Estadual de Campinas

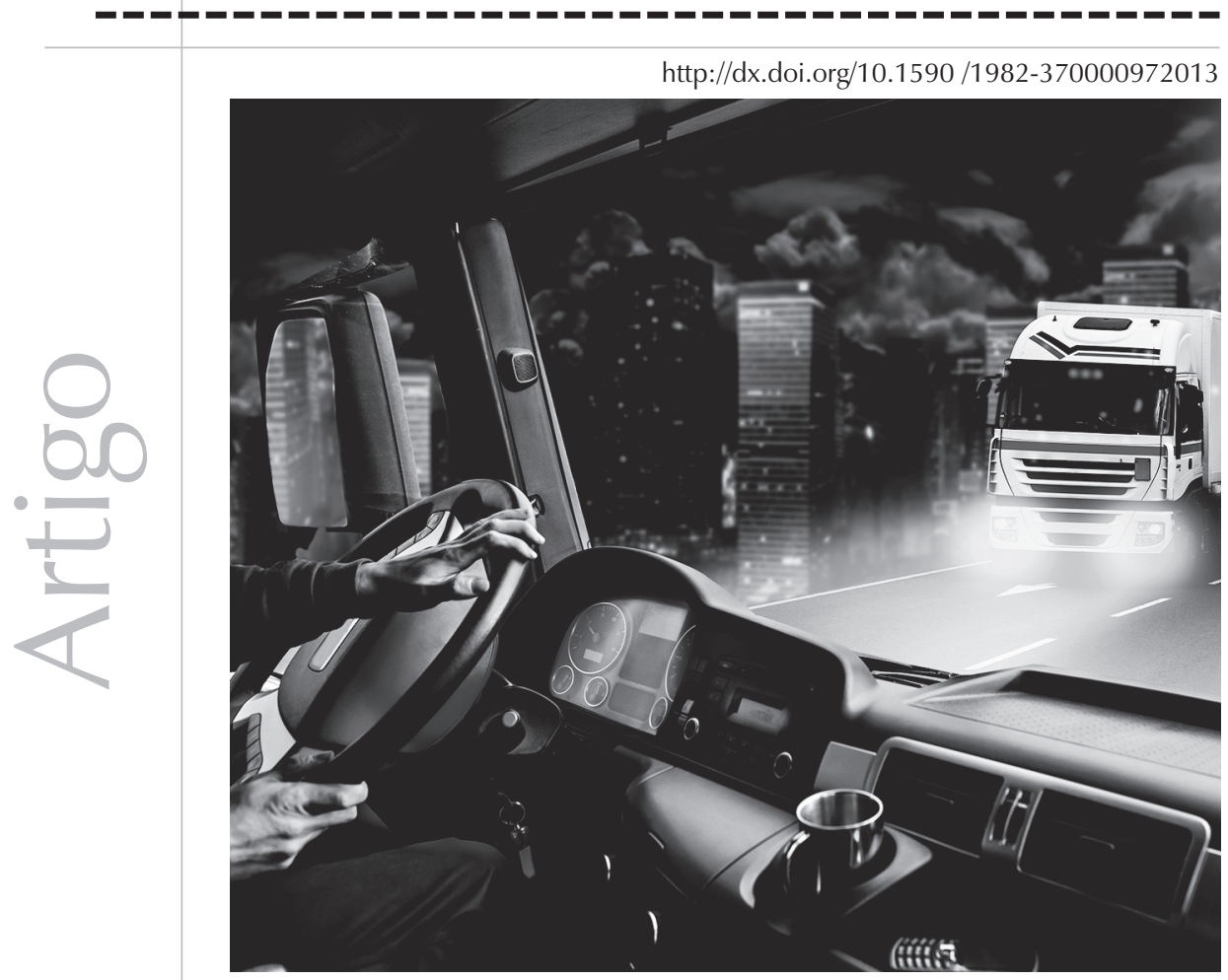


Resumo: O objetivo do estudo foi analisar quais valores centrais estão presentes nas representações de si de trabalhadores motoristas de caminhão. Participaram da pesquisa 17 motoristas de caminhão de uma empresa de transporte de cargas. Foi utilizado um roteiro de entrevista semidirigida e as respostas foram analisadas e categorizadas segundo as técnicas da análise de conteúdo. Os resultados demonstraram que os valores estão relacionados à ética no que se refere às categorias a si como pessoa e como motorista, mas não como empresa e concluiu-se que existe a necessidade de se criar oportunidades que favoreçam o "desenvolvimento" pessoal e profissional, mas que cabe também à empresa propor ações cooperativas e democráticas para que esse desenvolvimento seja de fato efetivo.

Palavras-chave: Desenvolvimento moral. Valores. Representações de si. Motoristas de caminhão.

Abstract: The study aims at analyzing which core values are present in representations of themselves for truck drivers. Seventeen truck drivers from a freight transportation company participated in the survey. A semi-structured interview script was used and the responses were analyzed and categorized according to content analysis techniques. The results showed that values are related to ethics regarding the categories of the self as individual and as drivers, but not as company. Thus, one concluded that there is the need to create opportunities favoring personal and professional "development", but it is also left to the company to propose cooperative and democratic actions for this development be really effective.

Keywords: Moral development. Values. Representations of the self. Truck drivers.

Resumen: El objetivo del estudio fue analizar cuáles son los valores centrales que están presentes en las representaciones de sí mismos de trabajadores conductores de camión. Participaron en la pesquisa 17 conductores de camión de una empresa de transporte de cargas. Fue utilizado un guión de entrevista semidirigida y las respuestas fueron analizadas y categorizadas según las técnicas del análisis de contenido. Los resultados demostraron que los valores están relacionados a la ética en lo que se refiere a las categorías el sí como persona y como conductor, pero no como empresa y se concluyó que existe la necesidad de crear oportunidades que favorezcan el "desarrollo" personal y profesional, pero que cabe también a la empresa proponer acciones cooperativas y democráticas para que ese desarrollo sea de hecho efectivo. Palabras -clave: Desarrollo moral. Valores. Representaciones de sí. Conductores de camión. 
A sociedade atual vivencia inúmeras transformações e, dentre elas, pode-se destacar o mundo globalizado, a preocupação com o aquecimento global, o desenvolvimento sustentável e, consequentemente, com a qualidade de vida das pessoas (Bauman, 1999; Câneo, 2005; Limongi-França, 2010). Inseridas nessas transformações destacam-se as ocorridas no mundo do trabalho em que as discussões giram em torno da alta produtividade, mas sem desconsiderar o trabalhador, embora na prática não se saiba bem como articular ambas as dimensões.

De acordo com Srour (2005), as organizações são vistas como instrumentos para atingir propósitos sociais, sejam unidades produtivas, políticas ou ideológicas. Essas características fazem com que as organizações possam ser vistas como ferramentas humanas, construídas e reconstruídas para lidar com os desafios do seu contexto, um empreendimento coletivo imerso em complexas redes de significados e interesses, tanto no plano dos indivíduos, com suas expectativas, habilidades e grau de importância, como no plano dos grupos, com suas dinâmicas que facilitam ou dificultam as suas atividades no plano organizacional; no conjunto de processos políticos e técnicos.

Kilimnik e Sant'Anna (2007), ao tratarem do tema da modernidade organizacional, mencionam que, frente às atuais transformações no mundo dos negócios, as organizações têm de valorizar as pessoas que nelas trabalham por suas competências e talentos. Touraine (2002) traz ideia semelhante quando diz que a modernidade foi definida pela eficácia da racionalidade instrumental, ignorando o sujeito humano como um ser criativo e possuidor de liberdade para tal e, com isso, estabeleceu-se a era de uma nova modernidade que pressupõe o resgate do sujeito.
Segundo Touraine (2002), essa perspectiva redireciona o homem para o centro da sociedade, compreendendo-o sob várias dimensões: social, administrativa, política, cultural e tecnológica. O sujeito, na dimensão social, é aquele que se insere nas relações sociais, transformando-as; na dimensão administrativa, define estratégias e metas; na dimensão política, possui noção de democracia e respeito à cidadania; na dimensão cultural, compreende fatores éticos e valorização do ser humano; e na dimensão tecnológica, abrange a tecnologia como instrumento para um desenvolvimento sustentável, alinhando ao progresso e bem-estar.

Frente a esse panorama, verificam-se transformações nas organizações vinculadas ao transporte, inclusive as que empregam motoristas de caminhão, que vivenciam as reflexões da atualidade somadas às pressões de novas normas impostas pela legislação ambiental e pelo novo código de trânsito, tendo como objetivo direto e/ou indireto melhorar a qualidade deste, o que impõe uma nova conduta ao profissional, no que se refere ao cumprimento das leis de trânsito.

Em síntese, observa-se, de um lado, a exigência mundial impondo "normas" de conduta e, por outro, o trabalhador que as colocará em prática. Por isso, nota-se a importância de verificar quais são os valores centrais que norteiam as condutas desses profissionais, tendo como base a Psicologia Moral sustentada pela teoria piagetiana.

\section{Valores da perspectiva da Psicologia Moral}

Piaget (1994) estudou o lado racional da moral e verificou que esse universo é composto de tradições e hábitos impostos por gerações passadas, mas que, por meio do 
desenvolvimento da razão, pode-se contrabalançar essas tradições e hábitos, submetêlos à crítica, transformá-los e até mesmo aperfeiçoá-los. Esse aperfeiçoamento está no campo valorativo que faz parte da ciência da moralidade.

La Taille (2006) apresenta a Psicologia Moral como uma ciência que busca desvendar os processos mentais por meio dos quais a pessoa legitima, ou não, os valores, as regras e os princípios morais. O ser humano, graças a sua capacidade de tomada de consciência de si, é capaz de dividir-se em um "eu" e um "me", sendo ao mesmo tempo sujeito e objeto: eu me vejo, eu me julgo. É por meio desse me que o eu se concebe, o que foi denominado de Representações de si, por Perron (1991 citado por La Taille, 2006).

Este conceito, representações de si, apresenta três características. A primeira pertence à ordem simbólica, que implica apreender a si próprio por meio de substitutos do objeto apreendido, ou seja, pensar o mundo por meio de noções, imagens e conceitos. A segunda pressupõe uma assimilação cognitiva, sendo o eu como objeto de conhecimento. As assimilações equivalem a interpretações sobre si podendo elas inclusive serem contraditórias entre si, mas que se relacionam. A terceira característica e a mais importante para o presente estudo é que as representações de si são valores e, segundo Piaget (1994), valor é definido como investimento afetivo e é também construído ao longo do desenvolvimento.

La Taille (2006) apresenta mais dois conceitos vinculados à representação de si: autoestima e autorrespeito. Compreende autoestima como qualquer estado subjetivo de valorização de si próprio e autorrespeito é quando a valorização de si próprio incide sobre valores morais. O autor vincula a ação moral ao respeito de si. A personalidade ética seria, nesse caso, aquela que tem valores morais associados à representação de si e ao valor de si.

Tognetta (2009) menciona que personalidade significa um conjunto de características de uma pessoa e é o que distingue uma pessoa de outra. De acordo com Perron (1985 citado em Tognetta, 2009), o conceito de personalidade é apresentado em três ideias centrais: a ideia de globalidade, que é o conjunto de características que identifica a pessoa, seu jeito, sua voz, enfim, seus signos particulares; a ideia de coerência, que implica a coerência interna que o sujeito apresenta; e a ideia de permanência no tempo, que nada mais é que sua história pessoal e é construída ao longo do desenvolvimento e das inúmeras interações que o sujeito tem com o meio.

Taylor (2005) considera que é necessário refletir sobre a própria identidade, o que implica situar-se perante valores para responder à pergunta: "quem sou eu", sendo que esses valores sempre colocam a oposição entre o bem e o mal, o desejável e o indesejável. A construção da identidade situa-se na busca de um valor positivo, condição necessária à realização da vida plena, e define a tese de que a moral é a associação de Eu, de Identidade e de Personalidade. No entanto, para La Taille (2004), aquilo que é desejável ou indesejável, o certo ou o errado, o bem e o mal estão relacionados às imagens que o indivíduo constrói. Isso tem grande repercussão psicológica visto que conhecer-se implica julgar-se. A personalidade moral seria, pois, o vínculo existente entre as representações de si e a moral, porque a construção dessas representações de si está na procura de valores, sejam quais forem.

A pessoa vê a si própria como valor e busca identificar-se com valores considerados por ela como positivos. Segundo La Taille (2006), o conjunto de representações de si é concebido como um sistema, no qual alguns valo- 
res têm maior importância para a pessoa, portanto, são considerados como centrais e outros, de menor importância, considerados como valores periféricos.

A descrição das representações de si enquanto sistema, no qual, certos valores são centrais e outros periféricos, permite aquilatar a forma motivacional desses valores, sendo que os centrais têm maior força motivacional, pois a pessoa deseja agir de forma condizente com eles.

Os valores podem ser analisados sob diferentes conteúdos. Tognetta (2009) investigou os valores por meio dos sentimentos de admiração e indignação enquanto sentimentos morais, referindo-se a motivação para agir e pensar moralmente, como também para definir sentimentos que podem decorrer de uma ação moral, ou não, ou seja, o contentamento com uma ação (admiração), ou seu contrário, descontentamento com uma ação (indignação). A indignação caracteriza-se por um sentimento negativo desencadeado por um juízo negativo feito por quem a experimenta e indica os valores que a pessoa tem.

Considerando as perspectivas atuais das organizações e a dimensão psicológica do trabaIhador que este estudo foi proposto. O objetivo da pesquisa foi analisar quais valores centrais estão presentes nas representações de si de trabalhadores motoristas de caminhão.

\section{Metodologia}

Participaram do estudo 17 motoristas de caminhão, com idades variando entre 35 a 65 anos, todos do gênero masculino, que exercem a profissão há mais de três anos e que trabalham há mais de dois anos na empresa selecionada para a pesquisa. Essa empresa é responsável pelo transporte rodoviário de cargas, cuja sede está situada em uma cidade no sul de Minas Gerais com filiais em vários estados do Brasil. Para o número de participantes foi adotado o método da amostragem por saturação, ou seja, quando os resultados começaram a parecer redundantes e repetidos do ponto de vista do pesquisador (Fontanella, Ricas, \& Turato, 2008).

Os instrumentos utilizados foram uma ficha de identificação, que teve como objetivo fazer a caracterização dos participantes quanto aos dados pessoais, de escolaridade e profissionais e um roteiro de entrevista semiestruturada, composto por questões referentes às ações que causam admiração, indignação e em três dimensões: como pessoa, como profissional e a empresa.

As questões foram: O que as pessoas fazem que lhe causa admiração e por quê? O que as pessoas fazem que Ihe causa indignação e por quê? O que um motorista de caminhão faz que lhe causa admiração e por quê? O que um motorista de caminhão faz que lhe causa indignação e por quê? O que a sua empresa faz que você admira e por quê? $\mathrm{O}$ que sua empresa faz que lhe causa indignação e por quê?

Após a aprovação pelo Comitê de Ética em Pesquisa (CEP), com parecer número 451011, iniciou-se a coleta de dados. Os motoristas foram abordados individualmente e todos os objetivos e procedimentos foram detalhadamente explicados, bem como os direitos dos participantes, ressaltando a garantia do anonimato.

Depois do aceite em participar do estudo, o pesquisado preencheu a ficha de identificação e depois de um breve rapport, iniciouse a entrevista sobre os valores que teve duração média de 20 a 30 minutos.

A presente pesquisa se enquadra na abordagem qualitativa. Os resultados foram apresentados também quantitativamente, o que 
permitiu analisar a frequência das respostas em cada categoria construída. As respostas foram analisadas e categorizadas segundo a Análise de Conteúdo, que, de acordo com Bardin (2004), é uma técnica de investigação que tem por finalidade a descrição objetiva e sistemática do conteúdo manifesto da comunicação. As respostas permitiram construir três categorias amplas, sustentadas pela teoria da Psicologia Moral: respostas sem conteúdo moral, com conteúdo moral e com conteúdo ético.

As respostas sem conteúdo moral foram aquelas que mencionavam características pessoais, traços de personalidade ou jeito de ser como sossegado, tranquilo, realista, estressado, solitário, normal, habilidade, entre outras de mesma natureza.

As respostas com conteúdo moral foram aquelas que mencionaram palavras de significado moral como "honestidade", "sinceridade", "trabalho", entre outras da mesma natureza, mas as justificativas estavam relacionadas ao cumprimento das regras e normas convencionais, como, por exemplo, "eu gosto das coisas muito certas", "obedeço às normas".

As repostas com conteúdo ético foram aquelas que sugeriram ser mais evoluídas do ponto de vista moral, cuja justificativa implica uma resposta que caracteriza alguma virtude e um querer agir moral que supera a obrigação e que denota relação de reciprocidade, que permite que a exigência de conservação de valores feita a outrem incida sobre as exigências do próprio sujeito, que vai exigir dele próprio a qualidade de ser digno de confiança, coerente e fiel a seus valores morais e capacidade de descentração, como, por exemplo, "ajudar as pessoas", "ser honesto", "agir com responsabilidade", "não prejudicar a empresa", "ter responsabilidade". As justificativas envolviam o "outro", que poderia ser a empresa, o colega ou a vida alheia.
Vale destacar que a diferença entre as categorias "com conteúdo moral" e "com conteúdo ético" é apenas de grau e acredita-se que ambas envolvem conteúdos morais, mas precisaram ser diferenciadas por inspirarem perspectivas diferentes. Essas só puderam ser avaliadas por meio das justificativas dadas às respostas. Para nomear essas duas categorias, a fim de diferenciá-las, buscou-se a própria teoria, mais especificamente, a diferenciação proposta por La Taille (2006) entre moral e ética.

Sobre as categorias, é preciso fazer uma ressalva: elas não implicam afirmar que os participantes estejam classificados em nível moral inferior ou superior, mas sim que suas respostas puderam ser categorizadas em uma dimensão de qualidade inferior ou superior, visto que é justamente isso que interessa no presente estudo.

Após o processo de elaboração das categorias de análise, as respostas foram relidas e julgadas nas categorias de forma independente por dois juízes e no caso de discordância, um terceiro juiz foi consultado.

\section{Resultados e Discussão}

Primeiramente, realizou-se a análise demográfica dos participantes e verificou-se que a média de idade dos participantes foi de 51,4 anos, sendo a idade máxima 65 anos e a idade mínima 35 anos, com desvio padrão de 21,21. Destes, $88 \%$ são casados e $12 \%$ são separados. Índice equivalente foi identificado sobre a escolaridade, sendo que $88 \%$ possuem Ensino Fundamental I (até 5 o ano) e apenas $12 \%$ possuem Ensino Fundamental II (até 9o ano). No que se refere ao tempo de profissão, observa-se que $35 \%$ situa-se entre 11 a 20 anos, outros $35 \%$ entre 21 a 30 anos. Observa-se que $53 \%$ trabalham na empresa entre 2 a 5 anos, sendo o tempo médio de trabalho na empresa de 8,4 anos. 
Após essa caracterização, optou-se por apresentar as questões que envolvem admiração e indignação, de forma comparativa e também na ordem estabelecida anteriormente, ou seja, sem conteúdo moral, com conteúdo moral e com conteúdo ético, referente às pessoas, aos motoristas e à empresa.

No que se refere ao que as pessoas fazem que lhes causam admiração, verificou-se que 11,8\% $(n=2)$ dos participantes deram respostas categorizadas em "sem conteúdo moral", com conteúdos como "autoridade", "homem da lei", "pessoas alegres", referindo-se a uma autoridade estereotipada, de vestimenta diferenciada, de traje e de comportamentos que não apresentavam virtudes morais. Referente à indignação, 17,6\% $(n=3)$ apresentaram respostas nessa mesma categoria, com conteúdos como: "várias coisas", "violência", "com quem fala palavrão".

Nas respostas categorizadas em com conteúdo moral, referente ao que admiram, 35,3\% (n=6) dos entrevistados apresentaram conteúdos como: "pessoas inteligentes", "pessoas educadas", "que tratam bem as pessoas" e "pessoas que cumprem as regras" e quanto à indignação, 17,6\% (n=3) apresentaram conteúdos como: "roubo" e "pessoas que não seguem normas estabelecidas".

Dos entrevistados, 52,9\% ( $\mathrm{n}=9)$ deram respostas categorizadas em com conteúdo ético, denotando, no que se refere à admiração, valor em ações generosas, justas e honestas, considerando a admiração como um sentimento positivo, de ordem moral e como condição necessária para o respeito a outrem e, $64,7 \%(n=11)$ se indignam com mentiras, fofocas, humilhações e desonestidades.

Ao comparar quantitativamente as respostas dadas referenciando o que lhes causa admiração e indignação, pôde-se observar que foi grande a porcentagem de respostas categorizadas em com conteúdo ético. O Quadro 1, a seguir, apresenta os exemplos de cada categoria comparativamente no que se refere à admiração e à indignação.

Quadro 1. Ação das pessoas que causam admiração e indignação

Categorias Admiração Indignação

SCM "- O que as pessoas fazem que the causa admiração? - Eu admiro a autoridade. A autoridade da pessoa quando um homem honrado mesmo, que toma frente que faz as coisas para povo entendeu? Que todo mundo fica admirado, eu admiro um homem da lei... Um homem bem trajado mesmo. Trajado que eu falo é que usa terno e gravata, um juiz, por exemplo." (M3) "(...) - Eu gosto de ver a pessoa curtindo, rindo, brincando, daí eu pareço uma criança no meio, assim conversando, isso me cativa, gosto de ver as pessoas alegres." (M6)
"- O que as pessoas fazem que the causa indignação? - Ah! Isso é difícil acontecer comigo. Ah! Isso não tem não. Para mim tá bom, sempre concordo. '- Vamos dormir? - Vamos. Vamos andar a noite inteira? - Vamos.' - Mas você não se indigna com nada? - Não! Para mim tá tudo bom, cada um faz do jeito que quiser." (M11). "(...) - Há tem várias coisas..., muita violência, coisa que a gente não aprova. Isso não traz futuro nenhum, só atraso de vida." (M13) 


\section{Categorias Admiração $\quad$ Indignação}

\section{$\mathrm{CCM}$}

CCE

Fonte: Pesquisa realizada pela autora.

Legenda: SCM: sem conteúdo moral; CCM: com conteúdo moral; CCE: com conteúdo ético; M significa motorista e o número se refere ao participante.
“(...) - Ah! Tanta coisa, roubo... roubo no País um país tão bom que é o Brasil, que tem de tudo para ser país de primeiro mundo, que fica jogado nas mãos das pessoas que só pensam em dinheiro, muito roubo..." (M2) “(...) - É a pessoa não está seguindo o ritmo que estou seguindo, se nós somos programados para andar num caminho, tem que andar todo mundo naquele caminho e andar todo mundo num passo só e se tem um no meio que está fazendo coisa errada, é de causar indignação não para todos, mas para aqueles que querem um caminho certo. E têm pessoas que vê a pessoa fazer coisa errada, e tem vontade fazer, e dá apoio." (M10)

“(..) - O que a pessoa pode fazer o que me causa indignação? Ah! Abandonar a família tem muito motorista aqui que fez isso aí viu?(M8) “(...) - Mentira, tipo levar vantagem, sabe? Tem pessoa que acha que... vem querer fazer sua cabeça, querer desfazer de você. Não é que eu seja inteligente, mas burro eu também não sou. Assim acha que... está querendo te convencer, quer te mudar, às vezes, assim, quer te convencer a fazer uma coisa errada é... pessoa desonesta eu não gosto." (M15) 
Referente às ações de um motorista de caminhão que lhes causam admiração, verificou-se que $23,5 \%(n=4)$ dos participantes deram respostas categorizadas em "sem conteúdo moral", cujos conteúdos se referiram à condução de "caminhões novos", motoristas "que trabalham direito", "que conseguem realizar boa manobra" e por motoristas que se apresentam com "boa aparência física". No que se refere à indignação, não houve respostas nessa categoria, o que é um dado importante, visto que se indignam com algo que corresponde a um valor moral. Esse resultado era, de certa forma, esperado porque dificilmente há indignação por ações não morais, a não ser quando as consequências delas impliquem em dano ao outro.

Ao analisar o percentual da próxima categoria, verifica-se que $35,3 \%(n=6)$ deram respostas "com conteúdo moral" para admiração e 23,5\% $(n=4)$ para indignação. Os conteúdos que surgiram para admiração foram: serem "prudentes", "honestos" sem expressar a ética, ter "cuidado", que "obedecem às normas de trânsito" e são "responsáveis". Os conteúdos relacionados à indignação referiram aos que dirigem alcoolizados, que não respeitam os outros, com desonestidade e que essas condutas colocam em risco a vida das pessoas, imprudência por conduzirem com alta velocidade, ultrapassagens arriscadas.

Para a categoria com conteúdo ético, 41,2\% $(n=7)$ dos motoristas deram resposta com esse conteúdo para admiração e 76,5\% $(n=13)$ para indignação. No primeiro caso, os motoristas admiram quem trabalha com atenção, de forma correta e com honestidade (sugerindo a prática do roubo), os motoristas que respeitam o trânsito e colaboram com o outro e também aqueles que corrigem o outro. Nessa questão, surgiram fatos interessantes que vão desde questões voltadas ao desempenho profissional (qualificação) a questões relacionadas à apropriação indébita, uma prática que os entrevistados afirmam que existe, mas que não apreciam. É importante lembrar que essa categoria se diferencia da anterior pela qualidade que pode ser compreendida nas justificativas. No segundo caso, os motoristas se indignam com os colegas que não respeitam a fila para carregar ou descarregar o caminhão, com pessoas desonestas que ficam chamando outros para fazerem coisas erradas e também com os que põem em risco a vida do outro nas estradas.

Vale ressaltar que a maioria das respostas dos entrevistados, tanto na questão sobre o que Ihes causam admiração como as que thes causam indignação na conduta (ações) de motoristas, foi categorizada em com conteúdo ético, o que é um aspecto positivo, visto que admiram o respeito às normas das estradas e a outrem e se indignam com a falta de respeito e desonestidade. Os exemplos de cada categoria foram organizados comparativamente, admiração e indignação, no Quadro 2. 


\section{Categorias}

\section{Admiração}

\section{Indignação}

"- O que um motorista de caminhão faz que Ihe causa admiração? - Ele estar bem vestido, cabelo feito, barba feita, porque ele é a cara da firma." (M6)

"(...) - Ah! Esses dias eu vi um rapazinho novo aqui, daí eu admirei ele por ser novo e manobrar uma carreta. Porque ele começou ontem, se você vê você admira. Isso é força de vontade." (M11)

\section{CCM}

“(...) - Ah! O que me causa admiração, já é aquela palavra de novo entendeu? Tudo se resume de uma coisa só, é o cara que anda certo entendeu? - Fazendo o que? Como que ele vai andar certo? - Uai! É trabalhar certo, ser honesto, ser justo, o caminhão tem que ser limpo, o caminhão tem que andar certo também. Porque a gente vê muito por aí, encontra por aí, o caminhão tudo apagado (sem luzes), isso aí eu não admiro. O motorista tem que ser prudente, eu admiro os motoristas prudentes, aqueles que andam certo entendeu, às vezes pode ser um carro pequenininho, pode ser com uma carreta. O grande valor é um só... é uma coisa só entendeu? O jeito de dirigir tem que ser um só." (M3)

"(...) - A tranquilidade da pessoa, a calma para dirigir, procurar sempre manter distância no trânsito, procurar sempre andar mais tranquilo para evitar certos tipos de acidentes. Que obedece sempre as normas de trânsito." (M13)
"- O que Ihe causa indignação na conduta de outro motorista? - De outros motoristas? É... tem muitos que fazem isso com a gente, dar uma fechada na estrada. Não todos, mas têm alguns. Passa às vezes sem dar sinal, sem nada já entra na frente da gente, então, é bastante, é bastante humilhante." (M1)

“(...) - O que me deixa irritado é a imprudência, por exemplo, eu vou indo aqui e o motorista assim, como já aconteceu várias vezes, como eu já trabalho bem tempo já aconteceu, o cara fecha eu sem motivo entendeu só por ruindade, vingança, ou não sei, então eu acho isso uma coisa muito ruim..." (M3)

“(...) - É que muitos passam além da velocidade, mesmo em estradas sinalizadas, e muitos passam além da velocidade." (M13) 
Categorias

\begin{abstract}
"(...) - Motorista que trabalha certinho, que não leva para esses lados aí a coisa. Que trabalha e presta atenção só naquilo que ele está fazendo ali. E não leva para esses lados ruins de beber, entendeu? Mexer nas coisas que não são dele, da empresa, entendeu? (...) Tem uns motoristas que são assim, que são bons, você pode por tudo na mão deles e virar as costas." (M8)

"(...) - Ah! Respeitar, eu acho que quando você está indo aí, quando você vai fazer uma ultrapassagem e não dá, o que me irrita é que, às vezes, nós temos o controle de excesso de velocidade, e você para na traseira de um caminhão e não pode ultrapassar. Cada um anda do jeito que quiser, eu admiro a pessoa que respeita no trânsito, dá preferência para outro. Se a gente quiser mudar, tem que ser assim, um vai colaborando com o outro." (M14)

“(...) - O que sabe trabalhar, saber fazer uma ultrapassagem, saber corrigir o erro dos outros entendeu? (...) Eu acho que a gente tem que corrigir entendeu, tem que respeitar, (...) um motorista trabaIhando desse jeito eu admiro porque é um profissional." (M17)
\end{abstract}

“(...) - A pessoa que quer descarregar depressa para carregar de novo, passando na frente dos colegas deixando para trás, e se fizer isso comigo eu não ligo, mas... eu fico assim... é! Eu não gosto." (M9)

"(...) - Pessoas desonestas, que ficam chamando as pessoas para fazer coisas erradas e você não quer fazer e fica te deixando constrangido. Tem gente que trabalha desonesto, começa a vender coisa que não é dele, fazem coisas erradas." (M10)

“(...) - Vários! Vários! Por exemplo, na pista está lá a placa de $80 \mathrm{~km}$ por hora e você está respeitando aquela lei, e o outro chega, e te passa, e não olha o local que ele está ultrapassando é perigoso, te fecha na estrada, te joga pra fora da estrada. Então isso aí me causa indignação, no meu caso, pra mim, isso causa indignação." (M12)

Fonte: Pesquisa realizada pela autora.

Legenda: SCM: sem conteúdo moral; CCM: com conteúdo moral; CCE: com conteúdo ético; M significa motorista e o número se refere ao participante. 
No que se refere às ações da empresa que lhes causam admiração, pode-se verificar que as respostas categorizadas se dividiram quase que de forma igualitária. Dos participantes, 35,3\% $(n=6)$ denotaram respostas categorizadas em sem conteúdo moral, 23,5\% (n=4) em "com conteúdo moral", 41,2\% (n=7) em "com conteúdo ético". Referente ao que lhes causam indignação, as respostas categorizadas em "sem conteúdo moral" foram significativas, totalizando 76,5\% (n=13), 5,9\% (n=1) em "com conteúdo moral" e $17,6 \%(n=3)$ em com conteúdo ético.

A fim de exemplificar as categorias em termos dos conteúdos, na categoria "sem conteúdo moral" no que se refere à admiração, surgiram bons equipamentos, nome forte da empresa e organização. No entanto, os entrevistados se indignam em viajar para lugares que não conhecem e também com a estrutura física das filiais, principalmente no que se refere aos banheiros e à falta de alojamento para descanso, além dos problemas relacionados com as programações das folgas que possibilitam o descanso e o contato com a família, em decorrência da falta de organização.

As respostas categorizadas em com conteúdo moral denotaram conteúdos como: tratamento com educação, trabalho com qualidade, cumprimento dos deveres e obrigações e pagamento correto. Com relação à indignação, as respostas denotaram que existem problemas com a falta de preparo de motoristas, que a empresa cresceu e que os problemas não são resolvidos. Houve uma queixa quanto ao distanciamento entre a direção e os motoristas, impossibilitando as reivindicações.

Nas respostas que foram categorizadas em com conteúdo ético, relacionadas à admiração, os conteúdos foram: cumprem o combinado, dão condições para trabalhar, o gerente resolve os problemas, liberdade, diálogo e pagamento em dia. Relacionado à indignação com a empresa, as respostas apresentaram conteúdos como: não respeitar a folga, ter que brigar para ir para casa e fazer desconto no pagamento de uns e de outros não, o que consideram um desrespeito.

O Quadro 3 apresenta os exemplos.

Quadro 3. O que a empresa faz que lhe causa admiração e indignação

\begin{tabular}{lll}
\hline Categorias Admiração & Indignação
\end{tabular}

SCM "-O que a empresa faz que Ihe causa admiração? - O que eu admiro na empresa? Eu admiro que ela tenha um nome muito forte, é uma empresa boa." (M7)

"(...) - É bem organizada, em matéria de... Ah! Tem uma organização boa, né? Pelo tanto de caminhão que tem pelo tamanho que é. Eu acho que deram certinho, nessa parte administrativa da empresa, assim... Controla todos os caminhões, tudo certinho." (M8)

"- O que a empresa faz que Ihe causa indignação? - Sabe o que eu queria na empresa que eu não me sinto bem? É um local para gente chegar aqui e ficar a vontade, um banheiro, um local para gente dormir, um tipo de um alojamento, para você ficar sossegado, aqui até tem, mas tá muito bagunçado. A gente chega lá tá muito bagunçado não dá coragem nem de ficar lá, então acho que deveria dar uma organizada no negócio, deveria ter uma televisão boa para você assistir, uma coisa para tirar o stress, algumas coisas assim. Só dá uma melhorada no local onde a gente fica. Só isso." (M10)

“(..) - O que eu acho que acontece é que tem lugar que nós vamos descarregar, não tem um chuveiro para tomar banho, não tem um pátio, então fica difícil assim, não é?" (M7) 


\section{Categorias}

$\mathrm{CCM}$

CCE

“(...) - Para mim tem todas as qualidades. Tem nada que falar. Tem carro bom, gerente bom, não tenho que reclamar. Estou aqui há quatro anos e nunca tive problema na empresa eu acho. - Por que você acha que o gerente é bom? - Bom! Eles procuram sempre resolver os problemas da gente." (M1)

\section{Indignação}

"(...) - Cada pergunta que você faz... Veja bem! Às vezes eu fico indignado com alguma coisa, mas a empresa tem motivo de ser desse jeito, porque por causa do quadro de funcionário, porque o que eu estou te falando é que... O que se torna difícil na empresa são os motoristas mesmo entendeu? Porque você vê! Antes tudo era resolvido mais fácil, a empresa era pequena... Hoje a empresa é grande cada um pensa de um jeito, entendeu? Então, tem coisa que a empresa está apertando. - O que seria? - O que o motorista mais reclamam aqui hoje são diárias entendeu? São Km rodados, não é?" (M17)

"(...) - Logo no início eu peguei caminhão baú, daí eu bati e tá descontando, e tem gente que bateu e não tá descontando, entendeu? E isso me deixou indignado!" (M9)

“(...) - É chegava no dia de você ir embora se eles não deixassem você ir, você tinha que brigar entendeu? Você não pode responder pelos outros o problema era esse negócio de folga." (M14)

Fonte: Pesquisa realizada pela autora.

Legenda: SCM: sem conteúdo moral; CCM: com conteúdo moral; CCE: com conteúdo ético; M significa motorista e o número se refere ao participante.

Os valores avaliados por meio da admiração e indignação foram organizados na Tabela 1, o que permite demonstrar a porcentagem de resposta em cada categoria, nas dimensões pessoa, motorista e empresa.

Tabela 1. Ações das pessoas, dos motoristas e da empresa que causam admiração e indignação

\begin{tabular}{lllllll}
\hline Categoria & \multicolumn{2}{l}{ Pessoa } & \multicolumn{2}{l}{ Motorista } & \multicolumn{2}{l}{ Empresa } \\
& AD & IND & AD & IND & AD & IND \\
SCM & $11,8 \%$ & $17,6 \%$ & $23,5 \%$ & $0 \%$ & $35,3 \%$ & $76,5 \%$ \\
CCM & $35,3 \%$ & $17,6 \%$ & $35,3 \%$ & $23,5 \%$ & $23,5 \%$ & $5,9 \%$ \\
CCE & $52,9 \%$ & $64,8 \%$ & $41,2 \%$ & $76,5 \%$ & $41,2 \%$ & $17,6 \%$
\end{tabular}

Fonte: Pesquisa realizada pela autora. Legenda: SCM: sem conteúdo moral; CCM: com conteúdo moral; CCE: com conteúdo ético; AD: admiração; IND: indignação. 
Com base na Tabela 1, é importante refletir sobre os valores em cada dimensão: como pessoa, como motorista e com relação à empresa. Tanto na dimensão "pessoa" como "motorista", as respostas se concentraram na categoria com conteúdo ético, sendo que, para indignação, a porcentagem foi maior do que para a admiração. Quanto à empresa, os dados foram diferentes. Houve predomínio de respostas com conteúdo ético para admiração e sem conteúdo moral para indignação.

No que se refere à pessoa, os entrevistados demonstraram admiração por pessoas generosas, justas e honestas; como motoristas, refletiram admiração por honestidade e respeito, apontando para o primeiro caso, a prática do roubo e no segundo, o respeito às normas do trânsito, salientando que o descumprimento destas pode colocar a vida, própria e a de outros em risco. No que se refere à empresa, admiram o cumprir com o combinado e o pagamento em dia, o que implica em uma relação de confiança, portanto, com valor ético. Apresentaram também como admiração, as condições de trabalho, a liberdade e diálogo, o que dá a entender que existe respeito pelo trabalhador.

Quanto à indignação, na dimensão pessoa, surgiu a mentira, a fofoca, a humilhação e, mais uma vez, a desonestidade. Na dimensão motorista, as respostas não se diferenciaram muito, porque há indignação com falta de respeito e de honestidade. No que se refere à empresa, a indignação não recaiu sobre a ética, mas sim sobre as condições de trabalho.

Esses aspectos consistem em valores e podem ser pensados sob a ótica de serem centrais ou periféricos (La Taille, 2006). Os que são centrais norteiam as ações da pessoa e pensando dessa forma, pode-se inferir que os motoristas de caminhão analisados têm chances de terem condutas éticas.

Os resultados encontrados suscitam algumas análises. Para tanto, algumas falas foram retomadas a fim de deixar a análise mais compreensível ou apenas a referência foi mencionada.

Inicia-se pela própria lei que rege o trânsito no país. Instituída no ano de 1997, a Lei no 9.503 estabelece novas regras de condutas aos motoristas, muito diferentes dos costumes até então vigentes. Mudança de hábito implica muitas vezes em rever valores, questionar os novos paradigmas e, acima de tudo, aceitá-los. Em sua dimensão operacional os órgãos regulamentadores, como o Detran, oferecem cursos de reciclagem. As empresas também devem promover cursos específicos na preparação desses profissionais, pois eles estão frequentemente expostos a perigos. Atualmente, existem cursos de direção preventiva, direção defensiva, movimentação de produtos perigosos, direção econômica, entre outros, que são específicos para o tipo de veículo que irá conduzir. Esses cursos oferecem aos motoristas meios mais seguros para exercerem sua profissão, pois possibilitam conhecimento e conscientização inerentes à sua atividade profissional.

Acredita-se que esses cursos sejam necessários porque trabalham com aspectos da prática do motorista. No entanto, essa prática é bem mais ampla por envolver não apenas a garantia de uma boa habilidade, mas implica, sobretudo, a conscientização de sua aplicação e, portanto, envolve valores pessoais. No caso do trânsito, pode-se dizer que o valor maior é a vida porque é sabido que a má direção pode levar à perda dela. $\mathrm{O}$ trânsito envolve respeito às regras, às normas e essas devem ser internas e não regidas pelo medo da multa. O cumprimento da regra pelo medo da punição equivale a uma etapa 
do desenvolvimento moral que foi denominada por Piaget (1932) de heteronomia, ou seja, moral regida pelo exterior, pela obediência. Ao contrário, no caso do cumprimento da regra pela consciência de sua necessidade equivale a uma etapa superior da moralidade, a autonomia, em outros termos, o autogoverno. Seria desejável que todos os motoristas fossem cumpridores das regras por dever interno (autonomia). Se assim fosse, certamente muitos acidentes de trânsito poderiam ser evitados.

Uma resposta de um motorista ilustra essa discussão. M8 (Quadro 1) respondeu: "Tem uns motoristas que são bons, você pode por tudo na mão deles e virar as costas" aqui está implícito o autogoverno. Para Piaget (1977), a passagem da moral heterônoma para a autônoma não é uma operação simples, que ocorre por si só, pois ela se estabelece entre as pessoas, por meio das relações de respeito e cooperação. Algumas rotinas estabelecidas podem não ser compreendidas, mas simplesmente seguidas. Segundo Martins e Silvia (2009), as ações passam a ser produtos das interações indivíduo-sociedade e se o indivíduo tem como orientação correta a satisfação de suas necessidades pessoais, com maus atos ou necessidades físicas em detrimento de pessoas ou padrões, segue uma orientação egoística ingênua. Cabe aqui uma reflexão sobre a necessidade de se criar oportunidades para discussões sobre aspectos relacionados a valores morais, considerando as dimensões intelectual e afetiva como parte integrante e presente na vida em geral, nos aspectos pessoais e profissionais.

Outra discussão possível é sobre o sentimento de força de vontade. Dell' Agli (2008) explica esse conceito na teoria piagetiana e, segundo a autora, Piaget o compreende como regulação de forças entre duas tendências em jogo: uma forte, mas inferior e outra fraca, mas superior. No primeiro caso, estão os desejos imediatos; e no segundo, a necessidade, a obrigação. A regulação de forças só é possível quando há uma escala permanente de valores. Assim, as pessoas agem a partir dessa escala e se os valores morais e éticos forem centrais ou estiverem no topo dessa hierarquia, muito provavelmente vão agir dessa forma. Do contrário, não.

Outra consideração pode ser feita. M14 (Quadro 1) fala em respeito e colaboração, e M17 (Quadro 1) também fala em respeito e pontua sobre corrigir os erros dos outros, aspectos importantes quando se consegue perceber que no trânsito, uma atitude não pautada nessas normas pode provocar acidentes fatais. Ainda sobre o respeito, M9 (Quadro 1) aponta uma questão importante, que sempre está sendo discutida em outros meios, que é burlar a fila, tentar levar vantagem, que caracteriza falta de respeito a outrem, portanto, é ético. M10 (Quadro 1) e M12 (Quadro 1) apresentam como eixo central o respeito e honestidade, mas M10 (Quadro 1) enfatiza de forma interessante, quando diz que se sente constrangido quando alguém faz coisas que não compactua.

De acordo com Piaget (1994), a evolução para uma moral superior está na dependência do tipo de interações que estão sendo estabelecidas com o meio ambiente. Como forma de fomentar a discussão, as respostas dos entrevistados M1 (Quadro 2) e M2 (Quadro 2) envolvem também relações baseadas no respeito, como o auxílio na resolução dos problemas, sem imposições, mas sim com liberdade por meio de diálogos. Segundo Menin (1996), a discussão equilibrada de forma que cada pessoa possa colocar seus argumentos, ou rebater os dos outros, examinarem suas posições e as dos outros, possibilita conhecer, considerar, negar ou afirmar outros pontos de vista que não só os próprios. Isso é fundamental em um ambiente organizacional e Piaget (1994) há 
muito já mencionava a necessidade de ambientes que proporcionassem as trocas de pontos de vista.

Reflete-se, nesse momento, sobre a admiração e indignação. Pode-se observar que referente à admiração, os entrevistados valorizam a aparência física que denota certa imagem do motorista. Esse dado reflete importância, pelo fato de geralmente ser difícil o cuidado com a higiene pessoal, visto que, fora de casa, nem sempre conseguem ter fácil acesso a banheiros que proporcionem essa condição.

Em outra categoria (CCM), verifica-se em M10 (Quadro 1) e M17 (Quadro 1) que admiram pessoas educadas, que tratam os outros bem, o que evidencia o quanto eles valorizam as relações sociais, visto que eles vivem no dia a dia esses relacionamentos, mesmo considerando que a pergunta foi relacionada à admiração a outra pessoa e não como motorista. Eles consideram as pessoas envolvidas em seus relacionamentos diários, pois ora estão em um lugar, ora em outro, longe dos familiares e dos amigos em comum, por isso o acolhimento de outrem é muito importante e valorizado, pois tende a diminuir o sentimento de solidão e aumentar a segurança, caso necessitem de algo. La Taille (2001) refere-se à boa educação como polidez e a considera como uma pequena moral, uma vez que não é possível comparála às "grandes" morais, como, por exemplo, a justiça, mas é moral porque implica uma relação de respeito para com o outro, embora totalmente convencional.

Macedo (1996) ao tratar do tema das leis e das regras, discute-as do ponto de vista de elas serem ou não passíveis de negociação. Segundo o autor, uma das regras considerada inegociável é tratar os outros com educação e, no presente estudo, essa regra moral foi valorizada pelos motoristas quando disseram que ser tratados com educação os faz sentir bem. Nos dias atuais, pode-se dizer que há carência de polidez nas relações sociais. Não significa dizer que se deve voltar ao "respeito" de antigamente, pautado nas relações de autoridade, mas parece prevalecer o extremo oposto. Professoras são chamadas de tia e esse termo generalizou-se para outras pessoas, inclusive com sentido pejorativo. Pessoas de mais idade não aceitam ser chamadas por senhor ou senhora, porque esse tratamento pode significar velhice, condição temida na sociedade pós-moderna em que prevalece o culto à beleza, à jovialidade. Poucos dizem no dia a dia "por favor", "obrigado", "desculpa", palavras simples, que significam muito para as interações sociais.

Segundo Tognetta (2009), a admiração pressupõe haver incondicionalidade nas relações estabelecidas ou naquelas projetadas enquanto desejos, com isso, admirar é buscar no outro aquilo que se estima e preza como melhor. O motorista M15 expressa, em sua resposta, admiração por pessoas honestas, verdadeiras, sinceras, talvez porque essas virtudes possam transmitir confiabilidade nas relações, visto que a admiração inspira sentimento e, de acordo com Tognetta (2009), para Descartes, admiração compreende uma dimensão de afeição e as pessoas honestas e verdadeiras agirão de forma justa e equânime. Para M5 (Quadro 1), a honestidade é admirável e para M1 (Quadro 1), o ato de ensinar é de grande valor.

Outra discussão a ser feita é sobre a queixa dos motoristas sobre a organização e estrutura física dos locais (infraestrutura). Buscando relacionar com a qualidade de vida, vale mencionar que, para a Organização Mundial de Saúde (OMS), a expressão saúde significa a preservação da integridade física, mental e social - um completo bem-estar biopsicossocial -; a expressão Qualidade de Vida no Trabalho (QVT) designa o conjunto 
de ações que objetivam melhorias que neutralizem riscos à integridade física, mental e social dos trabalhadores em diferentes dimensões.

$\mathrm{Na}$ verdade, os motoristas se indignam com esse "desrespeito". A indignação é uma reação à injustiça, como promessas não cumpridas, palavra dada que é retirada. Segundo La Taille (2006), o indivíduo se coloca como um sujeito de direitos e qualquer forma de injustiça o indigna e, de acordo com Tognetta e Vinha (2009), sentese indignado quem considera que um direito foi violado, pois há um sentimento negativo em resposta a ações que o sujeito considera contrárias ao que ele valoriza. M9 deixa claro seu sentimento de indignação, quando se refere à injustiça sofrida e M14 (Quadro 3), quando fala que seu direito de descanso e convívio com a família foi violado. O relato de M14 (Quadro 3) mostra um aspecto importante dessa profissão, que é o abuso ao limite do corpo quando ultrapassam as horas estabelecidas para o trabalho de acordo com a lei que regulamente a jornada de trabalho. Dirigir cansado, além do permitido, por exemplo, coloca em risco a vida própria e a alheia e viola o direito a outras dimensões da vida que são tão importantes quanto o trabalho.

Sentir indignação, muitas vezes, é fator positivo e expressa os valores de forma mais contundente. Tognetta (2009), referindo-se às ideias de Tugendhat, ressalta que indignação é uma reação à ausência de uma competência moral, considerando conteúdos como respeito ou solidariedade e os motoristas se indignam quando o que veem não corresponde ao que se tem como valor, com isso, pode-se observar que tanto M3 (Quadro 3) quanto M13 (Quadro 3) não refletiram em suas respostas algo que pudesse denotar valor moral.

Referente à indignação, os exemplos abaixo podem demonstrar que os entrevistados desaprovam atos que têm como valor o "roubo", "fazer coisas erradas". Observa-se que o eixo central que norteia as respostas de M2 (Quadro 1) e M10 é o "roubo" e "andar certo". No caso de M2 (Quadro 1), foi considerado como sendo uma resposta moral porque a justificativa inspirou conteúdo convencional e M10 (Quadro 1) sente-se indignado com as pessoas que fazem coisas erradas e acrescenta a vulnerabilidade diante disso.

Para Tugendhat (1999), a ausência de senso moral impede a pessoa de envergonhar-se moralmente, bem como se indignar, porque indignar-se é buscar correspondência imediata entre os valores que se têm e os que se aspira no outro. As respostas remetem a uma reflexão interessante, por considerar um aspecto positivo, pois os motoristas se indignam com mentiras, fofocas, humilhações e desonestidades. Ainda sobre a indignação, segundo Tognetta e Vinha (2009), sente-se indignado quando se é vítima de uma ação considerada imoral, como, por exemplo, constatar que foi enganado, quando maltrata alguém. Os entrevistados demonstraram sensibilidade na esfera moral e M1 (Quadro 1) e M5 (Quadro 1) mostraram isso claramente, principalmente quando referiram que se indignam com pessoas que querem levar vantagem e com pessoas que apresentam segundas intenções.

Tugendhat (1999) refere-se à indignação de duas formas, a primeira é quando há a desaprovação de uma ação que fere um bem moral que distingue em si próprio e que se exige ao outro enquanto um bom atrativo. A segunda forma é que o sentimento corresponde à motivação moral, relacionado à norma em si e ao desejo de ser. Seria buscar uma correspondência entre os valores próprios e os valores que aspira que o outro tenha, e M15 (Quadro 1) reflete que se 
sente indignado quando alguém tenta lhe convencer a fazer algo que não corresponde aos seus valores.

No que se refere à empresa, nas respostas categorizadas em sem conteúdo moral, M8 (Quadro 3) admira a organização e o controle, o que facilita a execução de seu trabaIho, e M10 (Quadro 3) indigna-se com a desorganização e com a falta de estrutura física que possa alojá-los enquanto aguardam o carregamento ou descarregamento. Os motoristas ficam à disposição do cliente, não são atendidos de imediato e enquanto aguardam, em muitos locais, não possuem estrutura física que possibilitem o atendimento às suas necessidades básicas, como: banheiros, local para fazerem suas refeições, tomar banho, entre outras.

Nas respostas categorizadas em com conteúdo moral, M10 (Quadro 3) admira ser tratado com educação, cabe aqui ressaltar que os motoristas sentem necessidade de pertencer ao grupo de trabalho, de estabelecer contato, serem orientados, esclarecidos e bem tratados, e M12 (Quadro 3) se refere ao cumprimento dos compromissos como questão admirável. No entanto, M17 (Quadro 3) ressalta que compreende que a empresa tem compromissos, mas se indigna com o valor pago a eles, como ajuda de custo para fazerem suas refeições nas estradas, e cita também que, com o crescimento da empresa, o diálogo direto com os diretores ficou mais distante e isso inviabiliza as negociações entre empregado/empregador, por uma perspectiva mais humana, mais direta e menos burocrática.

Por outro lado, nas respostas que foram categorizadas em "com conteúdo ético", M1 e M2 (Quadro 3) admiram o bom contato e o diálogo com os gerentes. No entanto, M14 (Quadro 3) indigna-se com esses mesmos gerentes por não respeitarem seus dias de folga.
Para M9, o que lhe causa indignação é a injustiça, pois quando ocorre algum dano ao equipamento, caminhão, o motorista é o responsável, e ele se refere a situações em que teve de reparar o dano causado e a postura não foi a mesma com outro motorista. Vale ressaltar que o motorista responde civil e criminalmente por atitudes imprudentes, irresponsáveis e de negligência. Em caso de desrespeito às leis de trânsito e acidentes e de acordo com a Consolidação das Leis Trabalhistas (CLT), são responsáveis e devem reparar danos causados ao patrimônio da empresa, cabendo ao técnico de segurança, analisar as causas dos danos, das multas e dos acidentes, quando ocorrem.

Os motoristas investigados valorizam aspectos éticos, portanto, positivos. No entanto, no que se refere à empresa, ficou evidente que a indignação ainda é por aspetos que permitem o bem-estar, o respeito a si como pessoa com necessidades básicas. Ao se analisar a Pirâmide de Maslow (1943, citado por Spector, 2002) pode-se compreender essa queixa. Na base da Pirâmide encontram-se as necessidades fisiológicas, as mais prementes, e no ápice, as necessidades de autorrealização que se referem ao desenvolvimento de capacidades.

Sustentados em Piaget (1994), pode-se dizer que os motoristas construíram valores que implicam reciprocidade e descentração. Entretanto, faz-se necessário uma ressalva: a presente pesquisa não teve como objetivo avaliar o nível de desenvolvimento moral, o que consiste em uma limitação do estudo. Assim, dizer que os valores construídos são éticos não implica afirmar que estão em níveis mais evoluídos, mas sim que os motoristas elegeram esses conteúdos frente aos questionamentos apresentados.

Contudo, pode-se dizer que o juízo dos motoristas é bem próximo do desejável e grande 
parte demonstrou possuir valores condizentes com a ética. No entanto, é necessário considerar que julgar não é o mesmo que agir e Piaget (1994) ressaltou muito bem essa diferença. Em outros termos, as pessoas podem apresentar julgamentos evoluídos, mas, em uma situação de vida real semelhante, a ação pode não ser do mesmo nível. Essa lacuna poderia ser mais bem trabalhada dentro das empresas, com o trabalhador sendo visto, de maneira geral, como ser humano capaz de evoluir a partir das reflexões propostas em grupo e em um ambiente sociomoral democrático em que suas opiniões são ouvidas e, acima de tudo, consideradas.

\section{Considerações finais}

O motorista de caminhão é um dos grandes protagonistas do desenvolvimento econômico do país. Ao longo dessa pesquisa, pôde-se verificar que, no Brasil, o número desses trabalhadores está entre um milhão e oitocentos mil e dois milhões. No entanto, faltam levantamentos precisos e atualizados sobre esses trabalhadores, principalmente no que se refere ao seu universo cultural, social e psicológico. O propósito deste estudo foi justamente verificar as dimensões psicológicas representadas pelos valores centrais que norteiam as condutas desse profissional.

De acordo com Tognetta e Vinha (2009), a formação de valores morais ou éticos depende de algo além da tomada de consciência do dever e essa alavanca na motivação interna para a ação, chamada de sentimentos, que integram a personalidade. Os valores, na perspectiva piagetiana, são compreendidos como investimento afetivo e são construídos ao longo do desenvolvimento. Ao pensar no adulto, poder-se-ia refutar a ideia de desenvolvimento, mas, acredita-se que o trabalho nas organizações denominado de treinamento profissional deve considerar esta dimensão psicológica - o Eu - e dessa forma promover o desenvolvimento muitas vezes desencadeado por situações de conflitos vivenciados no cotidiano. Os adultos têm, sim, sua escala de valores estabelecidos, mas se fossem imutáveis não se poderia pensar em mudanças evolutivas no âmbito da vida do trabalhador.

Apesar de serem muitos os estudos sobre o significado do trabalho para o indivíduo, desenvolvimento sustentável e qualidade de vida, responsabilidade social e comércio justo, a humanidade padece pelo aumento da violência, seja ela de ordem física, psíquica ou moral, como, por exemplo, o assédio moral, a corrupção, a miséria, a criminalidade, entre outros. Segundo La Taille (1996), a obra de Piaget é a explicação de uma possibilidade de evolução do ser humano e da sociedade e sua contribuição para a humanidade não é desejada apenas no campo científico, mas, também, moral e político. 


\section{Luzia Teixeira Martins}

Mestre em Desenvolvimento Sustentável e Qualidade de Vida pelo Centro Universitário das Faculdades Associadas de Ensino. São João da Boa Vista, São Paulo - SP. Brasil E-mail: luziatmartins@hotmail.com

\section{Betânia Alves Veiga Dell' Agli}

Doutora em Educação pela Faculdade de Educação da Universidade Estadual de Campinas, São Paulo - SP. Brasil. Docente do Centro Universitário das Faculdades Associadas de Ensino. São João da Boa Vista, São Paulo - SP. Brasil

E-mail: betaniaveiga@uol.com.br

\section{Endereço para envio de correspondência:}

Rua Milton do Lago Garcia, 105 - Jardim Amarylis. CEP: 37705-214. Poços de Caldas/MG. Brasil.

Recebido 02/03/2013, 1a Reformulação 14/10/2013, Aprovado 16/10/2013. 
Bardin, L. (2004). Análise de Conteúdo. Lisboa-Portugal: Edições 70.

Bauman, Z. (1999). Globalização: as consequências humanas. Rio de Janeiro: Ed. Jorge Zahar.

Câneo, L. C. (2005). As transformações no mundo do trabalho e os desafios para a atuação do psicólogo junto às organizações. In Fonseca, D. C., Câneo, L. C, \& Correr, R. (Orgs.), Práticas psicológicas e reflexões dialogadas (pp. 135-145). São Paulo: Casa do Psicólogo.

Dell'Agli, B. A. V. (2008). Aspectos afetivos e cognitivos da conduta em crianças com e sem dificuldade de aprendizagem. Tese de doutorado. Faculdade de Educação, Unicamp, Campinas, SP

Fontanella, B. J. B., Ricas, J, \& Turato, E. R. (2008). Amostragem por saturação em pesquisas qualitativas em saúde: contribuições teóricas. Cad. Saúde Pública. Rio de Janeiro, 24(1): 17-27. doi: 10.1590/S0102-311X2008000100003

Kilimnik, Z. M., \& Sant'Anna, A. S. (2007). Modernidade organizacional, políticas de gestão de pessoas e competências profissionais. In Borges-Andrade, J. E., Abbad, G. S., \& Mourão, L. (Orgs.). Treinamento, desenvolvimento e educação em organizações e trabalho (pp. 85-96). Porto Alegre: Artmed.

La Taille, Y. (1996). A educação moral: Kant e Piaget. In Macedo, L. (Org.). Cinco estudos de educação moral (pp. 137-178). São Paulo: Casa do Psicólog.o

La Taille, Y. (2001). Desenvolvimento moral: a polidez segundo as crianças. Caderno de Pesquisa, 114 (nov.), pp. 89-119.
La Taille, Y. (2004). Vergonha: a ferida moral (2a ed.). Petrópolis, RJ: Vozes.

La Taille, Y. (2006). Moral e ética: dimensões intelectuais e afetivas. Porto Alegre: Artmed.

Limongi-França, A. C. (2010). Qualidade de vida no trabalho - QVT: conceitos e práticas nas empresas da sociedade pós-industrial (2a ed.). São Paulo: Atlas.

Macedo, L. (1996). O lugar dos erros nas leis ou nas regras. In Macedo, L. (Org.). Cinco estudos de educação moral (pp. 179208). São Paulo: Casa do Psicólogo.

Martins, R. A., \& Silva, I. A. (2009). Valores morais do ponto de vista de professores de ensino fundamental médio. In La Taille, Y, \& Menin, M. S. D. S. Crise de valores ou valores em crise? (pp. 185-198). Porto Alegre: Artmed.

Menin, S. (1996). Desenvolvimento moral: refletindo com pais e professor. In: Macedo, L. (org.), Cinco estudos de educação moral. ( pp. 37-104). São Paulo: Casa do Psicólogo.

Piaget, J. (1994). O juízo moral na criança. São Paulo: Summus Editorial.

Piaget, J. (1977). O desenvolvimento do pensamento: equilibração das estruturas cognitivas. Lisboa: Publicações Dom Quixote.

Spector, P. E. (2002). Psicologia nas organizações. São Paulo: Ed. Saraiva.

Srour, R. H. (1998). Poder, cultura e ética nas organizações. Rio de Janeiro: Campus.

Taylor, C. (2005). As fontes do self: a construção da identidade moderna. São Paulo: Edições Loyola. 
Tognetta, L. R. P.(2009). Perspectiva ética e generosidade. Campinas SP: Mercado das Letras.

Tognetta, L. R. P., \& Vinha, T. P. (2009). Valores em crise: o que nos causa indignação? In La Taille, Y., \& Menin, M. S. de S. Crise de valores ou valores em crise? (pp. 1545). Porto Alegre: Artmed.
Touraine, A. (1994). A crítica da modernidade. Petrópolis, RJ: Vozes.

Tugendhat. E. (1999). Lições sobre ética. Petrópolis, RJ: Vozes. 